\title{
Lack of association between OSAS and hypothyroidism
}

\author{
Turkan Mete $\cdot$ Yavuz Yalcin $\cdot$ Bulent Ciftci
}

Received: 15 May 2013/Accepted: 3 June 2013/Published online: 26 June 2013

(C) Springer Science+Business Media New York 2013

We thank Carratù et al. for their comments on our study. In our study, which investigated the correlation between obstructive sleep apnea syndrome (OSAS) and thyroid diseases, 150 polysomnographically diagnosed OSAS patients and 32 non-OSAS control subjects were evaluated. In this study, functional and ultrasonographic examination of the thyroid gland did not reveal any relationship between OSAS and thyroid disease [1]. Unlike the study of Bozkurt et al. [2], there was no difference in Hashimoto disease frequency between OSAS group and control group. However, the study of Carratù et al. revealed, compatible results with our study, that subclinical hypothyroidism and levothyroxine treatment did not change prevalence and severity of OSAS [3].

In the view of this information, although functional and ultrasonographical examinations of the thyroid gland revealed no significant correlation between OSAS and thyroid diseases in our study, OSAS and thyroid diseases must be kept in mind as two prevalent health problems of the adult population with significantly similar symptoms and possibility of incidental thyroid dysfunction must be considered.

\section{References}

1. T. Mete, Y. Yalcin, D. Berker, B. Ciftci, S. Guven Firat, O. Topaloglu, H. Cinar Yavuz, S. Guler, Relationship between obstructive sleep apnea syndrome and thyroid diseases. Endocrine. (2013). doi:10.1007/s12020-013-9927-9

2. N.C. Bozkurt, B. Karbek, E. Cakal, H. Firat, M. Ozbek, T. Delibasi, The association between severity of obstructive sleep apnea and prevalence of Hashimoto's thyroiditis. Endocr. J. 59(11), 981-988 (2012)

3. P. Carratù, S. Dragonieri, O.Resta, Lack of association between OSAS and hypothyroidism. Endocrine. (2013). doi:10.1007/ s12020-013-9977-z

T. Mete $(\bowtie) \cdot$ Y. Yalcin

Department of Endocrinology and Metabolism, Ministry of

Health, Ankara Numune Training and Research Hospital,

Ankara, Turkey

e-mail: turkanmete@yahoo.com

B. Ciftci

Sleep Disorders Center, Atatürk Chest Diseases, Thoracic

Surgery Training and Research Hospital, Ankara, Turkey 